\title{
The Features of Rhenium Deformation Behavior at Room Temperature
}

\author{
Peter Panfilov \\ Institute of Natural Sciences and Mathematics, Ural Federal University, Lenin ave. 51, 620083, Ekaterinburg, Russia \\ Received: June 09, 2020
}

\begin{abstract}
Being the refractory hexagonal close-packed metal, rhenium is characterized by the ductile deformation behavior in the single crystalline state, but sometimes it behaves like a brittle solid in the polycrystalline form. The plasticity of the polycrystalline rhenium depends on the share of the tensile stress in the loading scheme and varies from low under bending to considerable under shearing. The grain boundary sliding is the factor that limited the malleability of rhenium work-pieces; it occurs because the basal slip is the primary deformation mechanism in rhenium at room temperature, as it takes place in zinc and ruthenium.
\end{abstract}

\section{INTRODUCTION}

Materials science states that metal with the hexagonal close-packed (HCP) lattice is a ductile solid, weakly strengthening under mechanical treatment $[1,2]$. The mobile $<1120>$ dislocations that can move on both basal plane and prismatic plane are considerable plasticity sources in an HCP-metal $[3,4]$. The empirical rule speaks that the ratio between the lattice parameters $c / a$, which depends on the chemical bonding, governs the deformation behavior of an HCP-metal [1]. The basal slip and the prismatic slip make the main contribution to the HCPmetal's plasticity when the ratio is close to the ideal proportion (1.63). In contrast, the basal slip becomes the dominating deformation mechanism when this proportion becomes higher than 1.85 [1]. Mechanical twinning is another channel for stress accommodation in a crystalline solid, but its contribution to a HCP-metal's total plasticity is minor compared to the dislocation slip [2]. Deformation behavior of the refractory HCP-metal rhenium $\left(T_{\text {melt }}=3186{ }^{\circ} \mathrm{C} ; \mathrm{c} / a=1.614\right)$ does not meet this rule. It is a plastic solid in the single crystalline state [5], while it demonstrates almost zero plasticity in the polycrystalline form at room temperature [6]. Both basal slip and prismatic slip are the dominant deformation mechanisms in the single crystalline rhenium [7]. These stress accommodation channels are also active in a polycrystalline rhenium [8,9]; however, this circumstance does not influence its total plasticity. This contradiction became the puzzle of rhenium, which is not solved until the present time [10]. Discussion of the rhenium problem is the aim of this paper.

\section{METALLURGY OF RHENIUM}

It is well-known that refractory metals' deformation behavior is highly sensitive to the non-metallic contaminants in the metallic matrix. The dangerous impurities such as $\mathrm{C}, \mathrm{H}$, and $\mathrm{O}$ induce the dramatic lowering of the grain boundaries' cohesive strength and, hence, dropping a refractory metal's plasticity [11]. This circumstance makes the processing of refractory metals more complicated than that of metals with low and average melting points. Therefore, the stage of deep refining is the most critical procedure in the manufacture of rhenium and other refractory metals [12]. The electron beam melting $(E B M)$ is an effective method for the pyrometallurgical refining of metals whose melting points are higher than $2000^{\circ} \mathrm{C}$ from non-metallic impurities [13]. EBM ingots with a coarse grain structure can be used

\footnotetext{
Corresponding author: P. Panfilov, e-mail: peter.panfilov@urfu.ru
} 
as work-pieces to manufacture rolling and wire from such refractory metal as iridium [14]. Another technology applied for refractory metals processing, including rhenium, is the powder metallurgy (PM) [6]. Therefore, both high pure PM metal and EBM metal are materials appropriate for mechanical treatment. The content of nonmetallic impurities in the EBM rhenium is about $10 \mathrm{ppm}$ that allows excluding the effect of impurity-induced fracture. However, EBM Rhenium is an unmalleable material at low homological temperatures, including room temperature. On the contrary, PM metal is applied to manufacture rhenium wires and sheets despite the fact that its impurities contents is higher than in the EBM rhenium.

\section{PLASTICITY OF THE SINGLE- CRYSTALLINE RHENIUM}

Analysis of a single crystal's deformation behavior is significant for examining the deformation mechanisms activated in a metal $[3,4]$. Single-crystalline rhenium exhibits some plasticity under tension (few percent of elongation) by the dislocation slip at room temperature, while deformation twinning accompanies its plastic deformation [5]. It is reported to be the usual behavior of an HCP-metal in the single-crystalline state, excepting a small elongation, which may be connected with the complicated procedure of the crystal growing used in this work, where the zone melting was applied.

The electron beam zone melting was also used to produce bulk rhenium single crystals [7]. The rhenium crystals were cylinders of $180 \mathrm{~mm}$ in length and $8 \mathrm{~mm}$ in diameter, they were grown along [1123], [1015], and [0001] axes. The electrochemical etching was applied to prepare the samples (the length of the working part was $15 \mathrm{~mm}$ and its diameter was $3 \mathrm{~mm}$ ) for the tensile testing. The deformation behavior of single-crystalline rhenium was examined under tension at 4.2, 77, 293, 523, 773, and $1273 \mathrm{~K}$, including attestation of its deformation mechanisms. The too-high data on the total plasticity were obtained for this refractory HCP-metal. The samples' total elongation was higher than $30 \%$ for all orientations and testing temperatures and could reach $300 \%$ at 1273 $\mathrm{K}$ for the [1123] and [1015] axes. The authors claimed that dislocation slip contributes to the plasticity of single crystals. However, the deformation twinning also makes a considerable contribution to the rhenium plasticity. It should be noted that the conclusion done in [7] does not meet the empirical knowledge on HCP-metals, because the contribution of deformation twinning to the total plasticity of an HCP-metal is minor compared to the dislocation slip [1,2].

The electron beam zone melting was used to grow a massive single crystal of rhenium $(20 \mathrm{~mm}$ in diameter

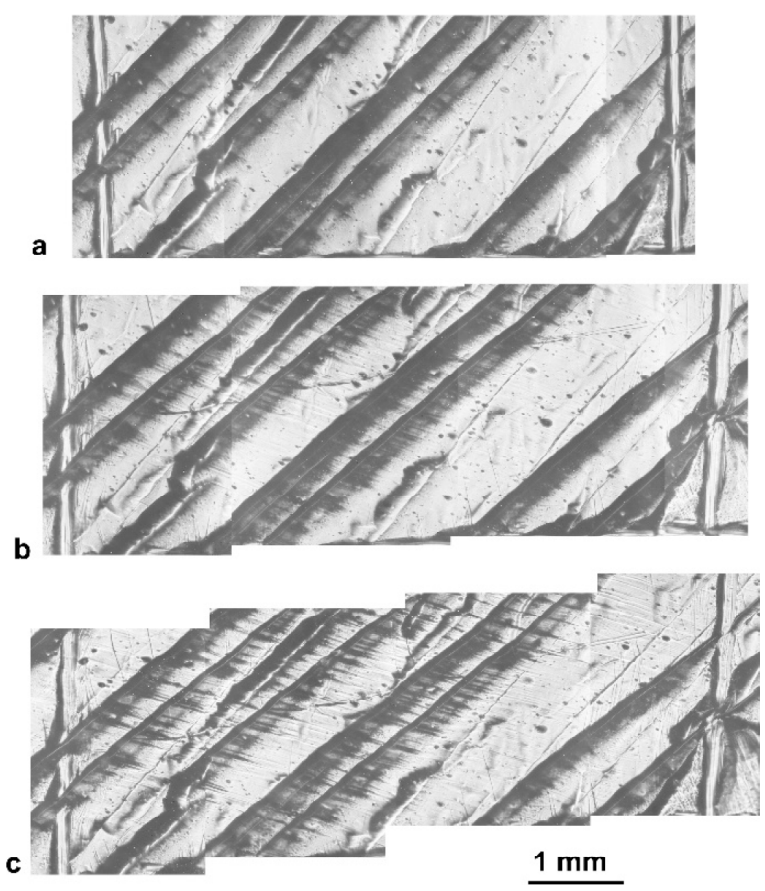

Fig. 1. Deformation tracks distribution in single-crystalline rhenium under tension: $\mathrm{a}-$ the initial state; $\mathrm{b}-1^{\text {st }}$ step ( $\sim 10 \%$ of elongation); $\mathrm{c}-2^{\text {nd }}$ step (torsion).

and $150 \mathrm{~mm}$ in length; it grew along the $a$ axis). The samples for testing (parallelepipeds with $30 \times 2 \times 2 \mathrm{~mm}^{3}$ ) were cut from the ingot by the spark erosion technique. Their tensile axis was parallel to the $a$ direction, and working surfaces laid in the basal plane. After cutting, the samples were mechanically abraded and electropolished. The Vickers microhardness was measured in every piece before and after mechanical testing. The work-piece for mechanical treatment was cut from the single crystalline ingot, but, in contrast to iridium, this approach did not allow to produce successfully processed rhenium [15].

Due to the highest microhardness in the initial state (7 GPa), the stress-strain curve of a rhenium single crystal under tension could not be built. The samples were creeping from the grips of the tensile facility. However, the metallographic examination allowed estimating the rhenium samples' total plasticity and describing the deformation defects that appeared under loading before and after the testing. The rhenium sample's back surface in the initial state and after the loading is demonstrated in Fig. 1. The reference lines inflicted on the pieces give information on the sample elongation. It was shown that the rhenium single crystals exhibited 10$15 \%$ of extension; after that, they began bending and intensively creeping from the grip. The Vickers microhardness increases to $10 \mathrm{GPa}$ at the elongation stage, while it did not change on the stage of bending. The metallographic examination has shown that the ba- 


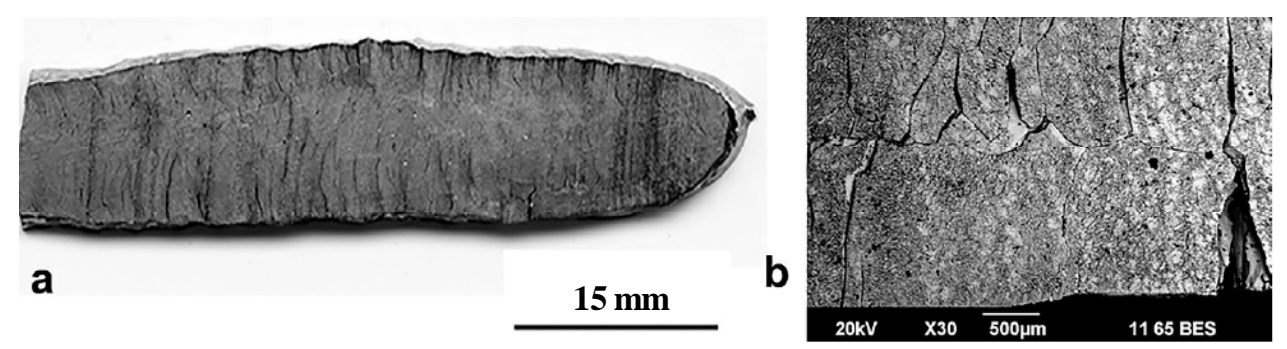

Fig. 2. EBM rhenium work-piece after the cold rolling: a - view after 5\% reduction (optical microscopy); b intercrystalline cracks on the surface (scanning electron microscopy).

sal slip provides all samples' plasticity on the elongation stage. The samples' bending is accompanied by the appearance of twin lamella, whose geometry is the same as twins in the initial state. The results obtained are close to the data reported in [5]. The total plasticity of single-crystalline rhenium at room temperature is limited; at that, the main contribution makes the basal slip, while the influence of mechanical twinning is minor. It seems to be the usual deformation behavior of an HCPmetallic crystal, where the basal slip is the dominant deformation mechanism, such as zinc. The problem arising is that, according to the empirical rule, both basal and prismatic slip should be active in rhenium because its $c / a=1.614$.

\section{PLASTICITY OF POLYCRYSTALLINE RHENIUM}

According to the findings considered above, singlecrystalline rhenium behaves as a usual HCP-metal and, hence, it should be a malleable substance in the polycrystalline state. However, polycrystalline rhenium demonstrates low malleability at room temperature. Indeed, arc-melted rhenium [6] and EBM rhenium [16] exhibit zero plasticity at room and elevated temperatures, and, therefore, PM technology and electrodeposition technology are used for the manufacture of rhenium wires and sheets [6]. However, tensile testing at $1200^{\circ} \mathrm{C}$ in a vacuum has shown that sometimes polycrystalline rhenium could display the ductile deformation behavior [17], and, hence, it can be subjected to the mechanical treatment. The recent TEM study agrees with this statement because both basal slip and prismatic slip are the dominant stress accommodation channels in polycrystalline rhenium under tension and compression at room temperature $[8,9]$. The interaction between twin lamella and grain boundaries is the possible cause of low plasticity in the polycrystalline rhenium at room temperature [18]. However, this cause looks fairly exotic even for refractory rhenium since the mechanical twinning would not induce such dramatic changes in the deformation behavior of an HCP-metal, which is an intrinsically ductile substance [1-3].
The rolling is the primary technological procedure to manufacture metallic sheets and wires, it combines tensile and compression loadings. Usually, the rolling process is carried out at room or elevated temperatures with intermediate annealing. Therefore, most experiments on the mechanical treatment of polycrystalline rhenium were done under this deformation scheme. We used PM rhenium plates $(0.5 \mathrm{~mm}$ in thick with the grain size of 20 $50 \mu \mathrm{m})$ and $\mathrm{EBM}$ rhenium plates $(1 \mathrm{~mm}$ in thick with the grain size of 5-10 $\mu \mathrm{m}$ ) as work-pieces in a cold rolling experiment. Vickers microhardness of the work-pieces in the initial state was about $7 \mathrm{GPa}$. The rolling experiments have shown that PM work-pieces fail on many small pieces as soon as loading is applied. It confirms the rule that PM metal should be processed at elevated temperatures only.

On the contrary, EBM work-pieces withstood 15$20 \%$ compression per one pass or a few passes of $3-5 \%$ reduction per each. The microhardness of rolled EBM work-pieces increased up to $8 \div 9 \mathrm{GPa}$, while they never failed under processing. The limit ( $20 \%$ of reduction) was caused by the demand to prevent damage to the rolling mill's high strength steel rolls. Formally, the results obtained point to the considerable plasticity of EBM rhenium, which potentially could be processed at elevated temperatures. The metallographic examination of EBM work-pieces after the rolling has shown that their back surfaces are extensively cracked (Fig. 2). However, it should be noted that it is a special kind of grain boundary $(\mathrm{GB})$ cracking because the cracks were stable under loading. Usually, GB cracks in metals grow in a brittle manner that induces a low malleability or technological brittleness of a metallic material. A similar situation occurs under the cold rolling of coarse-grained zinc and cadmium, where the grain boundary sliding (GBS) occurs [1]. The tensile stress induces GBS, which limits the plasticity of the coarse-grained HCP-metal. Hence, its plasticity should be maximal if the level of tensile stress is close to zero.

This hypothesis is verified for the EBM rhenium under the following deformation schemes: (1) three points bending [19], (2) the shear testing [20], and (3) 


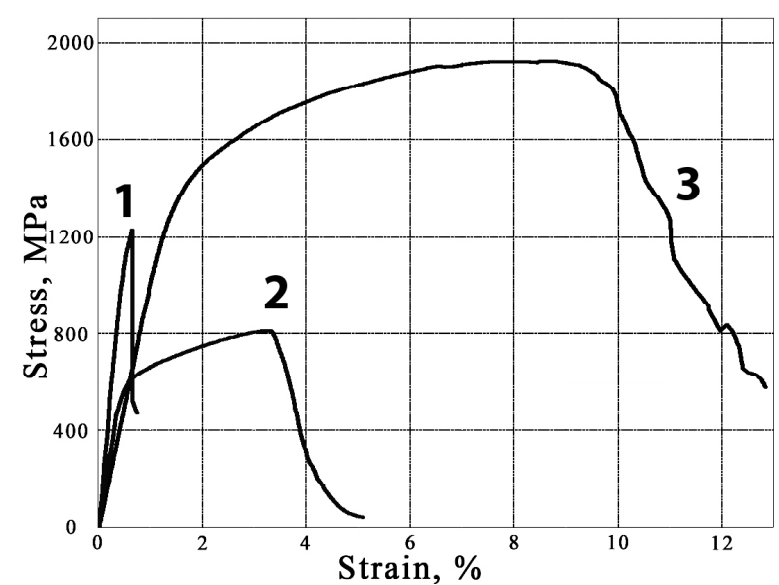

Fig. 3. Strength-strain curves under three points bending: curve 1 - EBM rhenium; curve 2 - PM rhenium; curve 3 - Ti-4Al alloy.

the high-pressure torsion (HPT) [21]. The experiments, where the portion of the tensile stress drops to zero under HPT, were carried out for PM rhenium, EBM rhenium, and coarse-grained Ti-4Al alloy. Stress-strain curves of the model materials under bending and shearing are given in Figs. 3 and 4, respectively. EBM rhenium exhibits a brittle deformation behavior under bending, where the portion of tensile stress is maximal, while PM metal and Ti-4Al alloy behave as a ductile solid. The drop in the tensile stress under shearing causes changing in the type of deformation behavior of EBM rhenium from brittle to ductile. When the tensile stress is absent in the loading scheme as it occurs under HPT, EBM rhenium behaves as a ductile metal and withstands a severe deformation despite a huge work-hardening; the stable nano-crystalline structure is forming in the initially coarse-grained EBM rhenium (Fig. 5).

\section{DISCUSSION}

The results obtained have shown that coarse-grained rhenium plasticity depends on the share of tensile stress in the loading scheme. It varies from a zero level in a brittle solid under bending to a highly ductile state under HPT. Excepting HPT, the dangerous crack in EBM samples is growing along the GB oriented perpendicularly to the tensile axis. However, it is not such a catastrophic growth as occurs under GB brittleness because the work-pieces could exhibit considerable plasticity. The most probable explanation of such deformation behavior is the influence of GBS. Indeed, this effect is inherent for coarse-grained HCP-metals, where the basal slip is the primary deformation mechanism. According to our investigations, rhenium meets this condition at room temperature, until it does not meet the conditions reported in [7-9]. However, this conflict with the

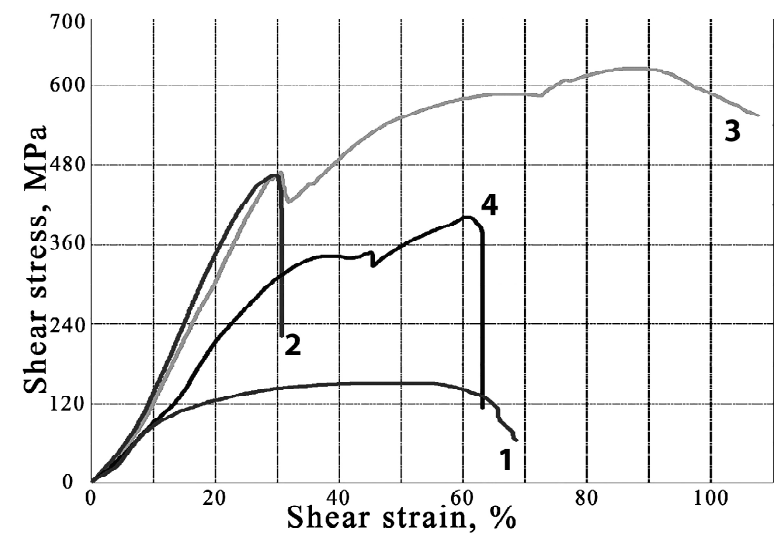

Fig. 4. Stress-strain curves under shear testing: curve 1 - polycrystalline copper; curve 2 - Ti-4Al alloy; curve 3 - PM rhenium; curve 4 - EBM rhenium.

empirical rule would not mean that it is not valid. It seems that the law was formulated exclusively for HCP-metals having low and average melting points.

In contrast, refractory HCP-metals were not examined in detail up to this time [1]. For example, another refractory $\mathrm{HCP}$-metal ruthenium $\left(T_{\text {melt }}=2334^{\circ} \mathrm{C}, \mathrm{c} / \mathrm{a}=\right.$ 1.568) also exhibits the basal slip as the dominant deformation mechanism at room temperature [22]. Perhaps, the basal slip as the primary deformation mechanism at low homological temperatures is the intrinsic property of a refractory HCP-metal.

Obtained results do not support the idea that power work-hardening causes a low malleability of rhenium. Of course, rhenium possesses the highest Vickers microhardness among the metals; however, plastic deformation does not induce its considerable growth excepting the case of severe deformation under HPT.

\section{ACKNOWLEDGMENT}

The Russian Science Foundation supports this work (\#18-19-00217).

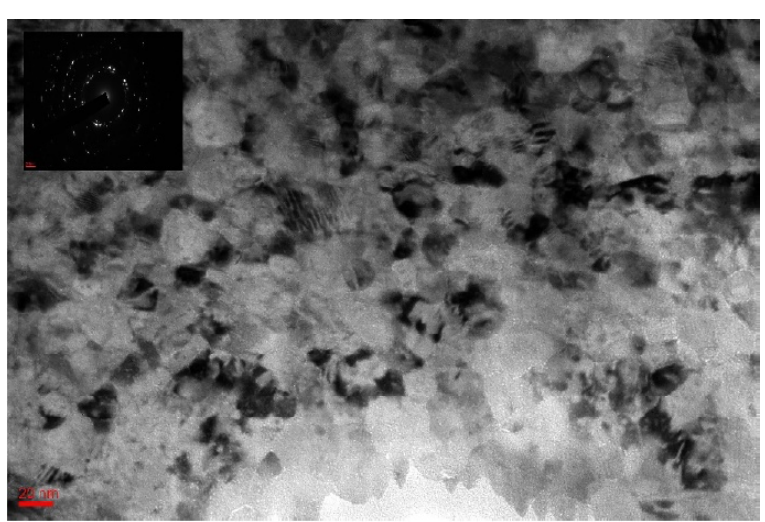

Fig. 5. Nano-grained structure formed in EBM rhenium after HPT at room temperature. 


\section{REFERENCES}

[1] R.W.K. Honeycombe, The plastic deformation of metals (London, Edward Arnold, 1968).

[2] A.S. Argon, Strengthening Mechanisms in Crystal Plasticity (Oxford, Oxford University Press, 2007).

[3] J. Friedel, Dislocations (Oxford, Pergamon Press, 1964).

[4] J.P. Hirth and J. Lothe, Theory of Dislocations (New York, McGrow-Hill, 1968).

[5] R.A. Jeffrey and E. Smith, Deformation twinning in rhenium single crystals, Phil. Mag., 1966, vol.13, no. 126 , pp. 1163 - 1168. https://doi.org/10.1080/ 14786436608213532

[6] C.T. Sims, C.M. Craighead and R.I. Jaffee, Physical and mechanical properties of rhenium, JOM, 1955, vol. 1, no. 1, pp. 168 - 179. https://doi.org/ 10.1007/BF03377474

[7] V. Kopetskii, M.M. Myshlyaev, N.I. Novochatskaia and Yukhanov, Study of plastic deformation of rhenium single crystals, Physics of Metals and Metallography, 1975, vol. 39, no. 1, pp. 164-174 (in Russian).

[8] J.E.C. Sabisch and A.M. Minor, Microstructural evolution of rhenium Part I: Compression, Materials Science \& Engineering A, 2018, vol. 732, pp. 251 - 258. https://doi.org/10.1016/ j.msea.2018.06.057

[9] J.E.C. Sabisch and A.M. Minor, Microstructural evolution of rhenium Part II: Tension, Materials Science \& Engineering A, 2018, vol. 732, pp. 259 272. https://doi.org/10.1016/j.msea.2018.06.059

[10] I.L. Shabalin, Rhenium, In: Ultra-High Temperature Materials I (London, Springer, 2014), pp. $317-358$.

[11] J.R. Handley, Increasing application for iridium, Platinum Metals Rev., 1986, vol. 30, Nn 1, pp. $12-13$. https://www.technology.matthey.com/ article/30/1/12-13/

[12] J-C. Carlen and B.D. Bryskin, Rhenium - a unique rare metal, Materials and Manufacturing Processes, 1994. vol. 9, no. 6, pp. 1087-1104. https://doi.org/10.1080/10426919408934977

[13] E. K. Ohriner, Rhenium and iridium, MCD ORLN, preprint No Conf-970201-6, 1996, 17 p. https:// digital.library.unt.edu/ark:/67531/metadc683240

[14] E. K. Ohriner, Processing of Iridium and Iridium Alloys. Methods from purification to fabrication,
Platinum Metals Rev., 2008, vol. 52, no. 3, pp.

186-197. https://doi.org/10.1595/

147106708x333827

[15] P. Panfilov, A. Yermakov, V. Dmitriev and N. Timofeev, Plastic flow of iridium, Platinum Metals Rev, 1991, vol. 35, no. 4, pp. 196-200. https://www.technology.matthey.com/article/35/4/ 196-200/

[16] R.I. Jaffee, D.J. Maykuth and R.W. Douglass, Rhenium and refractory Platinum-Group Metals, In: Refractory Metals and Alloys, AIME Metallurgical Society Conferences, vol. 11, ed. by M. Semchyshen and J.J. Harwood (New York, Interscience, 1961), pp. 383-463,

[17] I.S. Servi, Tensile ductility of rhenium at $1200^{\circ} \mathrm{C}$, J. Less-Common Metals, 1969, vol. 17, pp. 340 - 343. https://doi.org/10.1016/00225088(69)90155-6

[18] J. Kacher and A.M. Minor, Twin boundary interactions with grain boundaries investigated in pure rhenium, Acta Materialia, 2014, vol. 81, pp. 1-8. http://dx.doi.org/10.1016/ j.actamat.2014.08.013

[19] P. Panfilov, Yu.N. Gornostyrev, D. Zaytsev, G.P. Panfilov and V.P. Pilyugin, On deformation behavior of polycrystalline rhenium under three-points bending at room temperature, IOP Conf. Series: Materials Science and Engineering, 2019, vol. 581, art. 012028 (IOP Publishing doi: 10.1088/1757-899X/581/1/012).

[20] P. Panfilov, G.P. Panfilov and D. Zaytsev, Deformation behavior of polycrystalline rhenium under shear testing at room temperature, Materials Letters, 2020, vol. 277, art. 128379. https://doi.org/10.1016/ j.matlet.2020.128379

[21] P. Panfilov, T.P. Tolmachev, V.P. Pilyugin, Z. Chen and Z.L. Zhang, The forming of the ultra-fine grain structure in coarse grain rhenium under high-pressure torsion at room temperature, Materials Letters, 2020, in press.

[22] P. Panfilov and A. Yermakov, Plastic deformation and fracture of ruthenium single crystals, Platinum Metals Rev., 1994, vol. 38, no. 1, pp. 12-15. https://www.technology.matthey.com/ article/38/1/12-15/ 